\title{
COMPARATIVE ANALYSIS OF SPALTED AQUILARIA SINENSIS SPECIES WITH ZONE LINES PREPARED WITH XYLARIA VENOSULA
}

\author{
PAN, Z. H. ${ }^{1}-$ HE, H. S. ${ }^{2}-$ LI, Q. D. ${ }^{3}-$ QIU, J. ${ }^{2 *}$

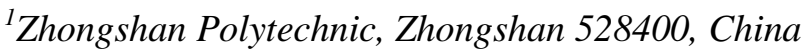 \\ ${ }^{2}$ College of Material Engineering, Southwest Forestry University, Kunming 6500224, China \\ ${ }^{3}$ Foshan University, Foshan 528000, China \\ *Corresponding author \\ e-mail: qiujianswfu@foxmail.com; phone: +86-137-5951-2363
}

(Received $7^{\text {th }}$ Jun 2019; accepted $10^{\text {th }}$ Oct 2019)

\begin{abstract}
In this paper, Xylaria venosula strains were inoculated separately into wood blocks of Alnus nepalensis, Betula alnoides, Aquilaria sinensis and Pinus kesiya, and induced artificially to create spalted woods with zone lines. The results showed that: (1) Aquilaria sinensis could easily form black zone lines, where the mycelia were denser than elsewhere. (2) The zone lines on and within Aquilaria sinensis were the most obvious when the wood blocks contained 50\% water. In this case, zone lines were rich and beautiful and the wood was not severely rotten. (3) The largest spalt was observed on Aquilaria sinensis blocks. This type of wood underwent the most serious spalting, with $6.64 \%$ of its surface and $1.84 \%$ of its interior covered by spalts. As the wood blocks rotted over time, the weight loss rates of spalted woods were on the rise, while the compressive strengths parallel to grain were gradually falling. The unitary linear regression shows significant correlation between the mass loss ratio and the compressive strength parallel to grain. It can be concluded that Xylaria venosula did not destroy the cell walls within the woods, and had little effect on the strength of the woods.
\end{abstract}

Keywords: Xylaria venosula strains, water content, weight loss rate, compressive strength, regression analysis

\section{Introduction}

Spalting is a manifestation of fungi causing discoloration of wood. The wood after discoloration is called Spalted wood. The spalting generally manifests in four types: white rot, stains, zone lines, and brown rots, and actually the first three have practical values. It mainly occurs on the felled wood, and also on the standing timbers under harsh environmental conditions. Generally, one or more of the above three types can be formed on the same piece of wood. Currently, spalted wood with rich zone lines are the most valuable in the foreign market. Xylaria venosula, making the wood coloring to form the mottling pattern, is onekindoffungususedtoformthe line-patterned varietal wood, which can form a unique decorative effect and a certain medicinal value.

The fungi that can form spalted pattern are mainly basidiomycetes and a few ascomycetes, and the polymorpha charcoal which can form the striatum line alone is often used in the laboratory to study the planting of Aquilaria sinensis. According to previous studies and speculations, Robinson et al. of the College of Forestry, University of Toronto, Canada, believe that the zone lines are the spalts formed as a defensive mechanism against the obstacle between the strains (Robinson et al., 2009); in their experiment, 25 species of fungi were isolated from the wood, and then incubated on an agar medium in pairs; where they produced a distinct pigment on the agar medium 
between the two fungi and the line of resistance between the two strains, the two fungi that formed zone lines on the medium were inoculated separately at both ends of the sugar maple block, for a total of 21 pairs of fungi combinations, two of which produced stable zone lines and white rot, that is, Bjerkandera adusta/Trametes versicolor and Polyporusbrumalis/Trametes Versicolor, while the fungi of the remaining 22 woody plants did not form stable spalts. In addition, Robinson et al. believe that the zone lines can be formed on any wood species. The broadleaf woods are whiter in colour, and the trees with low content of extracts are more likely to form spalting, such as Acer spp., Betula spp. and Fagus spp. (Xu et al., 2013). Robinson and Turnquist studied the Xylari polymorpha, which can form zone lines independently by inoculating it on Populus tremuloides, Acer saccharum, Betulaalleghaniensis and Tilia Americana; with the time extension on the medium, it is observed through the amount of spalts that Populus tremuloides and Acer saccharum produced more zone lines than the other two (Robinson et al., 2009).

Based on the concept of the spalted wood, this paper probes into the artificial preparation of spalted wood using the Xylaria venosula strain to infect the wood block, and then studies the related ways and characteristics of the strain infection. By inoculating Xylaria venosula strain on different kinds of woods, it focuses on comparing the similarities and differences of the formed zone lines, the influence of water content, wood property, weight loss, and spalting formation etc. Besides, it studies the formation and mechanism of the zone lines in spalted woods. Thus, the random variation of the surface lines on the spalted wood can help to produce the green, low-carbon, environmentally-friendly and beautifully crafted products and attaching veneers, and improve the comprehensive utilization and added value of the wood. This is of high economic value and social significance, and also lays a theoretical foundation for the stably and continuously acquiring the spalted wood.

\section{Materials and methods}

\section{Experimental materials}

Main material:

(1) The Xylaria venosula strain: purchased from the China Forestry Culture Collection Centre, and prepared by the screening test of fungal strains in the same genus or the same species, as shown in Figure 1.

(2) Wood specimens: they were collected from variety of trees such as Alnus nepalensis, Betula alnoides, Aquilaria sinensis, and Pinus kesiya on April 9 and 29, 2017 in Jindian Park, Kunming City, Yunnan Province, China, and nearby forests.

(3) Filtered water: It is filtered by YJD laboratory water purifier (Yongjieda Purification Technology Co., Ltd., Hangzhou, China) filter.

\section{Cultivating the fungus of spalted wood}

First, the liquid potato-Dextrose-agar (PDA) culture medium was placed into a $250 \mathrm{ml}$ triangle flask or culture bottle, for about $100 \mathrm{ml}$ per bottle, then autoclaved and sterilized for $30 \mathrm{~min}$ under high pressure. Afterwards, the Xylaria venosula was inoculated into the bottle, and cultured for 7-12 days using the thermostat oscillator SHA-B (A) (Chengdu Yike Instrument Equipment Co., Ltd., Sichuan, China), to obtain 
the bacterial suspension with a large number of agglomerated mycelia inside (Fournier et al., 2011; Osono et al., 2011; Zink and Fengel, 1988).

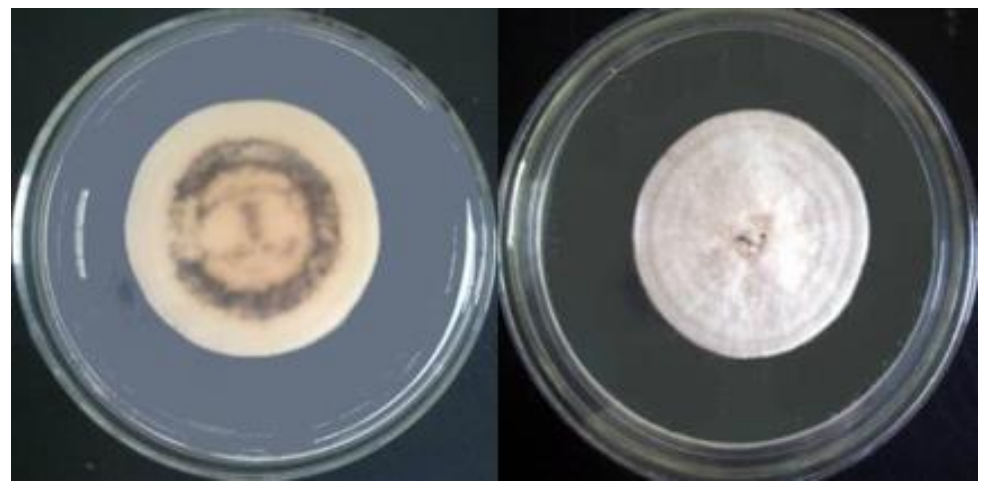

Figure 1. Morphological characteristics of the Xylaria venosula strain

\section{Pre-treating the inoculated wood block}

From the four easily spalted tree species of Alnus nepalensis, Betula alnoides, Aquilaria sinensis, and Pinus kesiya, 60 pieces of $30 \mathrm{~mm} \times 20 \mathrm{~mm} \times 20 \mathrm{~mm}$ wood blocks were taken respectively, for a total of 240, and placed into the bottle (Robinson and Laks, 2010), which was filled with appropriate amount of filtered water and then sterilized for $45 \mathrm{~min}$ in the YM30Z vertical autoclave (Sanshen Medical Instrument Factory, Shanghai, China), together with the cultural medium and the medium vermiculite.

\section{Inoculation of wood blocks}

First, cut the plate PDA strain into $10 \mathrm{~mm} \times 20 \mathrm{~mm}$ pieces, clip it with the tweezers and stick it on the wooden block, put it into the culture bottle and cover it with vermiculite, and add 10-25 $\mathrm{ml}$ of filtered water to wet the vermiculite and the wood block before fastening the cap. Then, for liquid inoculation, use the tweezers to clamp the wood block and cover the bacteria solution, cover it with vermiculite, add 10-25 ml of water to wet the vermiculite and wood block. Next, the inoculated wood blocks were placed in a constant temperature and humidity chamber (produced by Blue Sky Laboratory Instrument Factory, Hangzhou, China) at $27^{\circ} \mathrm{C}$ under dark conditions (Robinson and Laks, 2010), cultivating for about 80 days. Finally, take out the wooden block, scrape off its surface mycelium, wash and dry it, and observe whether there has formed a clear zone line inside and outside the block.

\section{Observing the characteristics of the spalted wood with zone lines}

The $10 \mathrm{~mm} \times 10 \mathrm{~mm} \times 10 \mathrm{~mm}$ blocks with rotten zones were taken from the four wood species of Alnus nepalensis, Betula alnoides, Aquilaria sinensis, and Pinus kesiya. They were sliced with German Leica 2000R slicer (Leica Microsystems Nussloch $\mathrm{GmbH}$, NuBloch, Germany), and stained by double staining to better observe mycelia (Pearce, 1984), then observed and recorded using an Eclipse 80i microscope. Besides, electron microscopy (HC300X type Shengtian Instrument Co., Ltd., Shenzhen, China) was used to observe the morphology and distribution of mycelia inside and outside the rotten area. 


\section{Analysis of wood microstructure}

From the four kinds of woods, namely, Alnus nepalensis, Betula alnoides, Aquilaria sinensis, and Pinus kesiya, $5 \mathrm{~mm} \times 5 \mathrm{~mm} \times 5 \mathrm{~mm}$ cubes were made, ensuring that the transverse section, radial section, and tangential section can be found on each wood block as much as possible. In our experiment, the wood block was softened first at a certain extent with hot water, then cut evenly at each face with a sharp blade without leaving any scratches, and finally undergo air drying at room temperature. Since the dried wood is basically non-conductive, in order to clearly observe the ultrastructure of the wood cell wall and the rotting degree of the strain Xylaria venosula in the wood tissue, it is necessary to metallize the surface of the wood block (Passarini et al., 2013). For the gold-coated wood blocks, the SEM-EDXA scanning electron microscopy (FEI Company, Eindhoven, the Netherlands) was adopted to observe the extent of damage to the wood cell wall by the activity of mycelium in the rotten area (Læssøe et al., 2013; Robinson et al., 2011).

\section{Experimental steps of wood water content}

The four types of wood blocks mentioned above were made into $2 \mathrm{~cm} \times 2 \mathrm{~cm} \times 2 \mathrm{~cm}$ squares with CS70EB precision woodworking table saw (FESTOOL, Germany). They were dried in a blast drying oven at $60{ }^{\circ} \mathrm{C} \pm 5{ }^{\circ} \mathrm{C}$, and then weighed. The vermiculite was dried to absolute dryness at $60{ }^{\circ} \mathrm{C} \pm 5{ }^{\circ} \mathrm{C}$. Through preliminary experiments, the relationship between the amount of water added and the water content of the wood block was obtained. Then, one specimen from each tree species, $10 \mathrm{~g}$ vermiculite, and unequal amount of filtered water were added to each culture bottle respectively. 5 pieces of blocks were prepared repeatedly for each gradient, sterilized in autoclave, and cooled for 6-8 $\mathrm{h}$ and weighed again. Then, the blocks containing the $10 \%, 30 \%, 50 \%$, $70 \%, 90 \%$ of water were prepared. The water content calculation formula is shown as (Tian et al., 2013):

$$
\mathrm{M}_{\mathrm{c}}=\left[\left(\mathrm{m}_{1}-\mathrm{m}_{2}\right) / \mathrm{m}_{2}\right] 100 \%
$$

$\mathrm{M}_{\mathrm{c}}$-water content; $\mathrm{m}_{1}$-mass at the end of the test $(\mathrm{g}) ; \mathrm{m}_{2}$-mass $(\mathrm{g})$ at the start of the test.

\section{Determining the average mass loss percentage}

Before inoculation, all the blocks were placed in a blast drying oven at $60{ }^{\circ} \mathrm{C}$ for 48 $60 \mathrm{~h}$ until reaching constant weight, and the mass $\mathrm{m}_{2}$ was weighed; after they're autoclaved at high temperature, inoculated and placed in a constant temperature and humidity chamber, infected by fungi for $4,6,8,10$, and 12 weeks, the blocks were taken out and the surface mycelium were scraped off, and then dried in a blast drying oven at $60{ }^{\circ} \mathrm{C}$ to a constant weight (Passarini et al., 2013; Læssøe et al., 2013), thus the mass $\mathrm{m}_{3}$ was weighed. Then, the average mass loss rate of the rotted wood block was calculated as (Robinson et al., 2007):

$$
\mathrm{L}=\left[\left(\mathrm{m}_{3}-\mathrm{m}_{2}\right) / \mathrm{m}_{3}\right] 100 \%
$$

L-mass loss rate; $\mathrm{m}_{2}$-mass at the start of the test $(\mathrm{g}) ; \mathrm{m}_{3}$-mass $(\mathrm{g})$ at the end of the test. 


\section{Determining compressive strength}

The blocks with the mass loss rate measured and the untreated healthy wood were dried in a blast drying oven at a temperature of $103{ }^{\circ} \mathrm{C}$ for more than $48 \mathrm{~h}$ until constant weight in an absolute dry state. The RGT-20A versatile experimental machine (REGER Instrument Co., Ltd., Shenzhen, China) was used to determine the compressive strength of the blocks. The experimental results are the average of 5 specimens according to the experimental standard ISO 3787-1976 Wood-Test MethodDetermination of Ultimate Stress in Compression Parallel to Grain (Liers et al., 2006).

\section{Unitary linear recursive analysis}

Unitary linear recursive analysis was conducted about the weight loss rate and compressive strength of the four tree species using SPSS18.0 software. The Pearson correlation coefficient between the two variables is less than 1, indicating a highly linear correlation between the two.

\section{Results and discussion}

\section{Morphology and distribution of mycelium in wood}

From the successfully cultivated spalted woods with black zone lines in the four species of trees, four samples were selected, as shown in Figure 2.

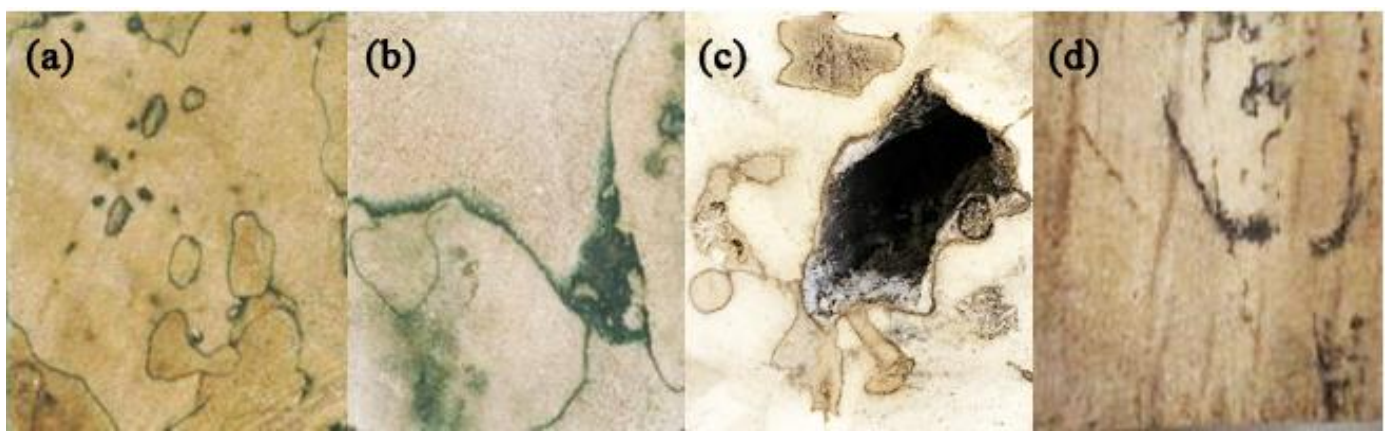

Figure 2. Visual characteristics of the artificially formed spalted woods' macrostructure. (a) Alnus nepalensis, (b) Betula alnoides, (c) Aquilaria sinensis, (d) Pinus kesiya

Figure 2 shows the micrograms of the spalted woods artificially cultivated from the four species of trees. The linear parts in dark colour were spalts. When the Xylaria venosula strain infected the woods, a large amount of melanin was excreted in their respective areas of the woods for mutual defences, producing black short lines, small spots, and irregular strips and forming bands, thereby forming the zone lines. Due to the extremely fineness of mycelium, it is easily damaged during slicing and cleaning, but the zone lines formed are still obvious. Therefore, if properly controlled, the sap stain fungi could be used to secrete the pigment, and colour the surrounding wood tissue. Thus, a beautiful natural pattern can be formed.

The micro-structure of artificially cultivated spalted wood was observed by light microscopy. 6 pictures in transverse section, radial section and tangential section were selected for research analysis, as shown in Figure 3. 
Figure 3 shows the morphology and distribution of mycelium in wood block under light microscope: a represents an area of distinct black zone lines in the radial section of Alnus nepalensis under 10-fold light microscope, and the area around the line was shallow in wood colour, significantly different from the area outside; one obvious feature was that the black zone lines extends outward at the wood ray. b represents the black zone lines in the radial section of Alnus nepalensis under the 40-fold light microscope, which was formed by the melanin secreted by the fungus in each wood tissue; the arrow refers to the mycelium filled in the duct within the zone line area, and the area outside the zone lines on the right has no difference from the normal wood, only with a small amount of mycelium distributed near the black zone line area. c indicates the V-shaped black zone lines in the tangential section of Alnus nepalensis under the 4-fold light microscope, and the $\mathrm{V}$-shaped inner area was light yellow, and the wood colour outside the V-shaped area was normal. $d$ represents the mycelial distribution at the black zone lines in the tangential section of Alnus nepalensis under the 40-fold light microscope, which clearly indicates that the mycelia were mainly distributed in ray parenchyma cells, axial parenchyma, and wood fibre connected with parenchyma cells, and the black zone lines were the macroscopic performance of the mycelia that are entangled into a group. However, in the wood fibre cells closely spaced from the mycelium (the area between the two arrows in the figure), there was very little mycelium distribution, which is more common in white rot fungi (Robinson et al., 2011; Tudor et al., 2012, 2013). This may be because there are fewer nutrients in the fibre cells, and the parenchyma cells are the tissues that transport nutrients in the wood, containing more starch, polysaccharides and oils; the fungus will not decompose the cell walls to absorb nutrients until these substances are completely decomposed. e represents the distribution of the black zone line in the transverse section of the Betula alnoides under the 4-fold light microscope. f represents the mycelial distribution of the black zone lines in the transverse section of the Betula alnoides under the 40-fold light microscope; it can be observed that there were many mycelia distributed in the fibre cells and wood ray cells, and a large amount of melanin was accumulated in the wood ray cells and cell walls.

\section{Microstructure analysis of spalted wood}

In the experiment, the black zone lines were successfully cultivated from the four species of trees. For each species, several sections were scanned and analysed.

Figure 4 shows the growth of Xylaria venosula in the Alnus nepalensis, where a represents the mycelial distribution in the duct lumen and wood fibre lumen, and $\mathrm{b}$ is the mycelial distribution on the pits inside the vessel element, $\mathrm{c}$ and $\mathrm{d}$ are the mycelial distribution of the vessel element and the wood ray in the tangential section of Alnus nepalensis.

Figure 5 shows the growth of Xylaria venosula in the wood of Betula alnoides, where $\mathrm{a}$ and $\mathrm{b}$ represent the mycelial distribution in the lumen of the duct and wood fibre, and c represents the mycelial distribution on the pit in the radial section, $d$ represents the mycelial distribution of vessel element and wood ray on the tangential section of Betula alnoides.

Figure 6 shows the growth of Xylaria venosula in the wood block of Aquilaria sinensis, where a and $\mathrm{b}$ represent the mycelial distribution in the lumen of the duct and wood fibre, and c represents the mycelial distribution on the pit inside the radial section, $\mathrm{d}$ represents the mycelial distribution of vessel element and wood ray. 

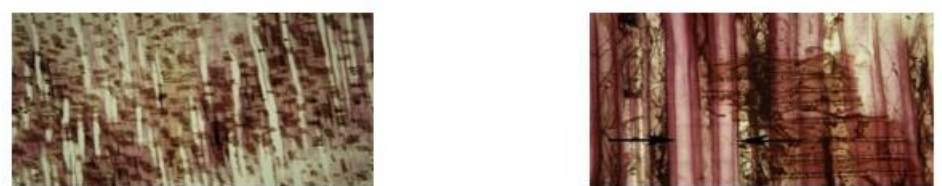

a Alnus nepalensis-Radial section (2X) b Alnus nepalensis-Radial section (40X)
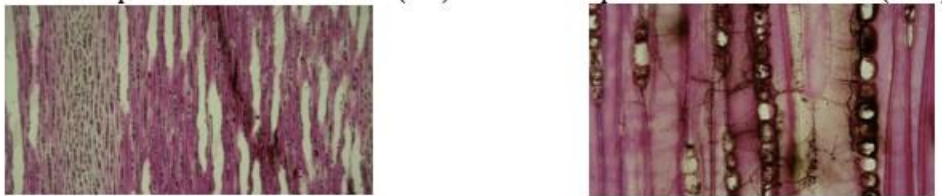

c Alnus nepalensis-tangential section (4X) d Alnus nepalensis-tangential section (40X)
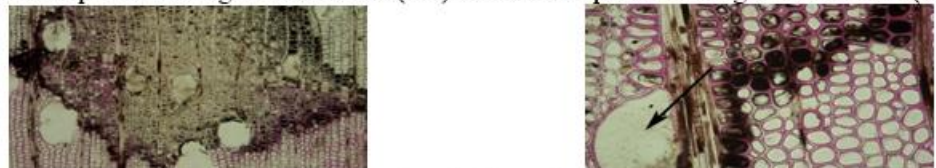

e Betula alnoides-transverse section (10X) f Betula alnoides-transverse section (40X)
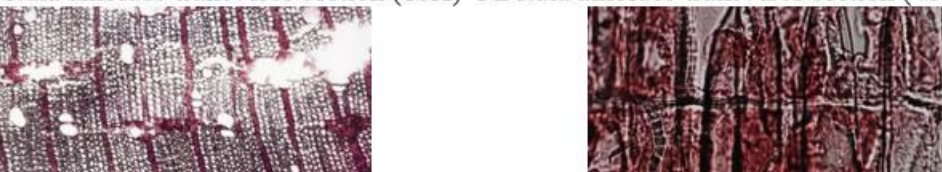

g Aquilaria sinensis-transverse section (10X) h Aquilaria sinensis-radial section (40X)

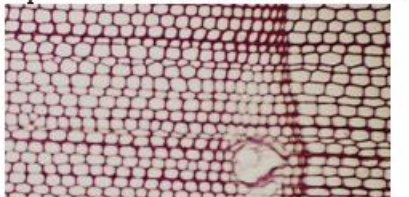

i Pinus kesiya-transverse section (20X) j Pinus kesiya-radial section (80X)

Figure 3. Morphology and distribution of mycelium in wood under light microscope
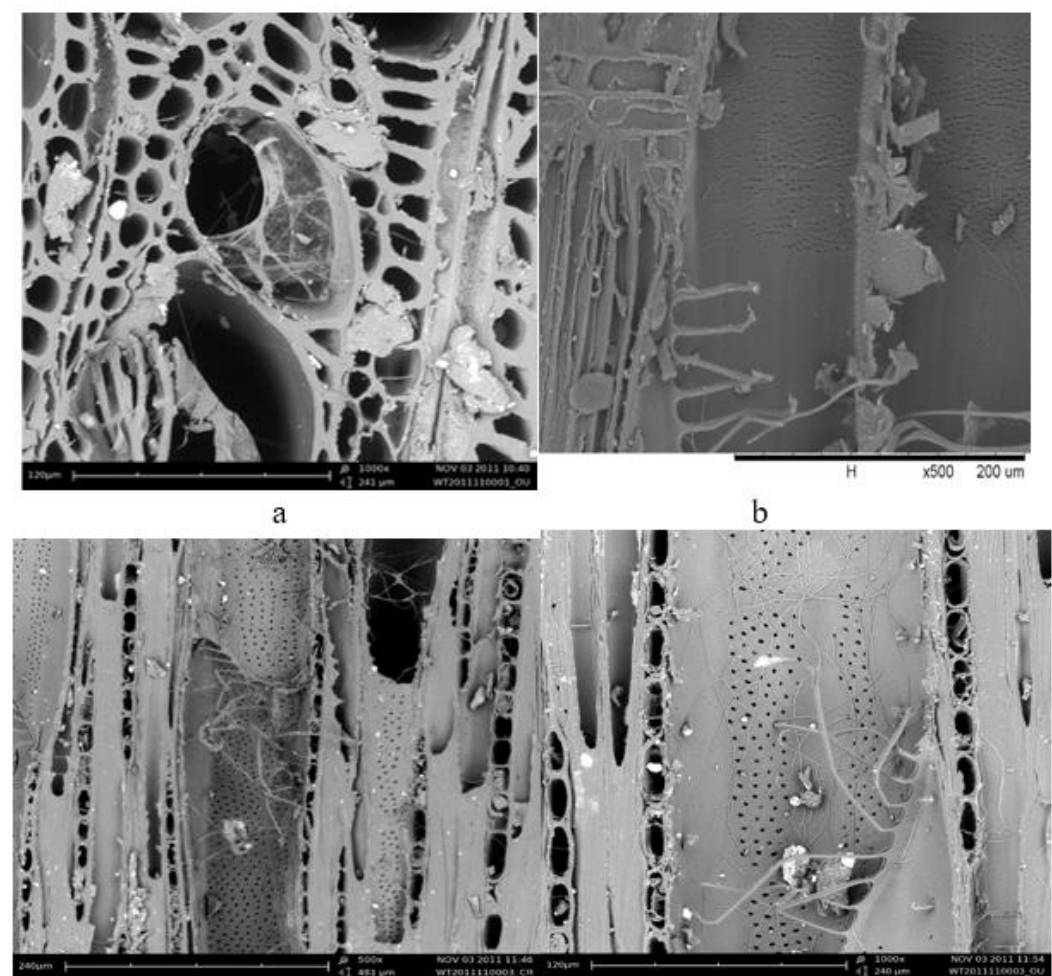

$\mathrm{c}$
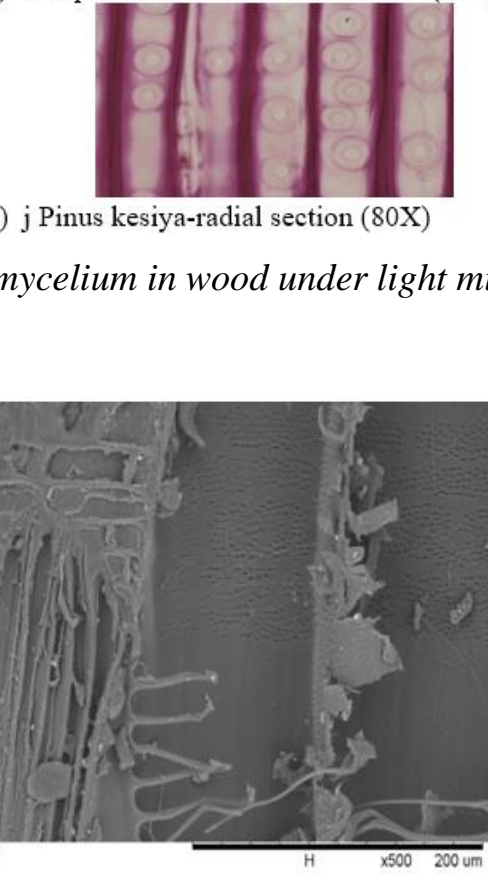

b

Figure 4. Influence of Xylaria venosula on wood structure of Alnus nepalensis 


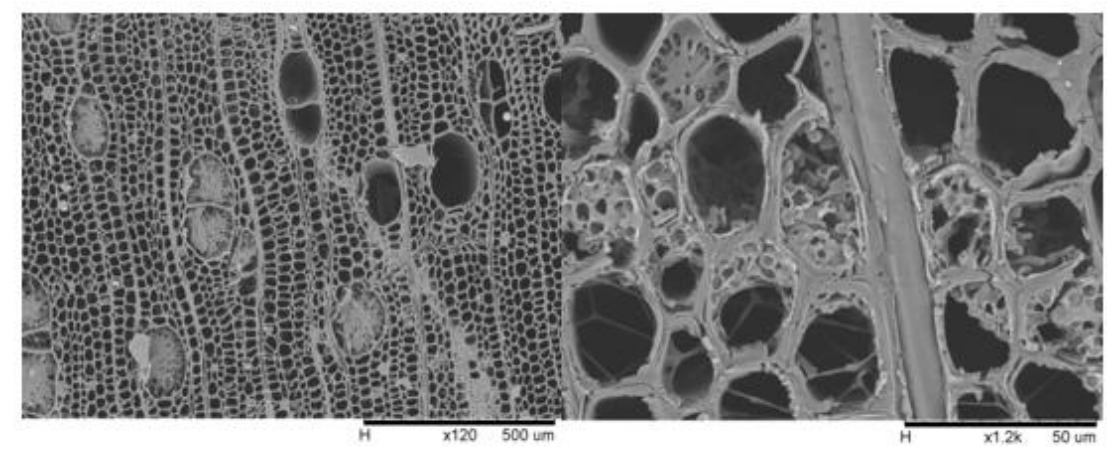

a

b

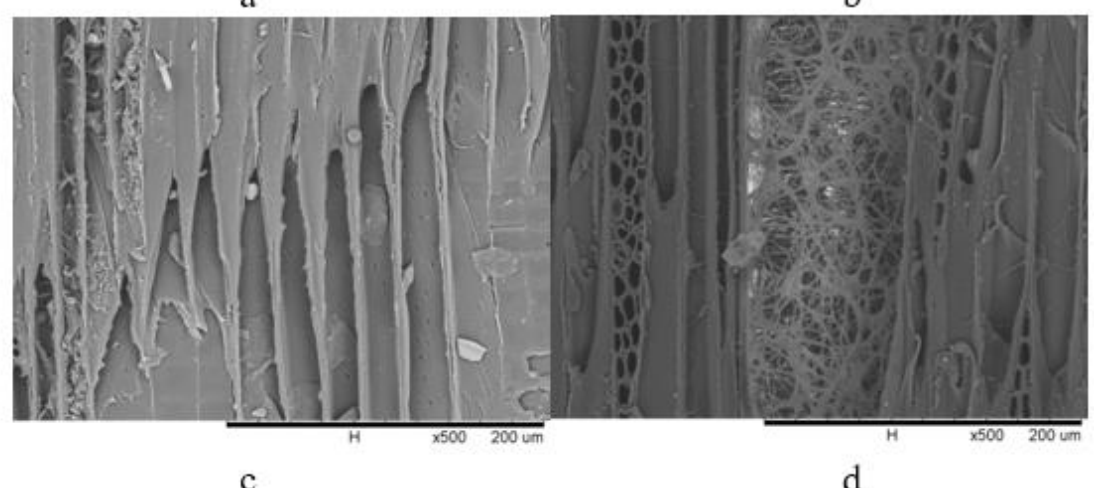

c

d

Figure 5. Influence of Xylaria venosula on wood structure of Betula alnoides

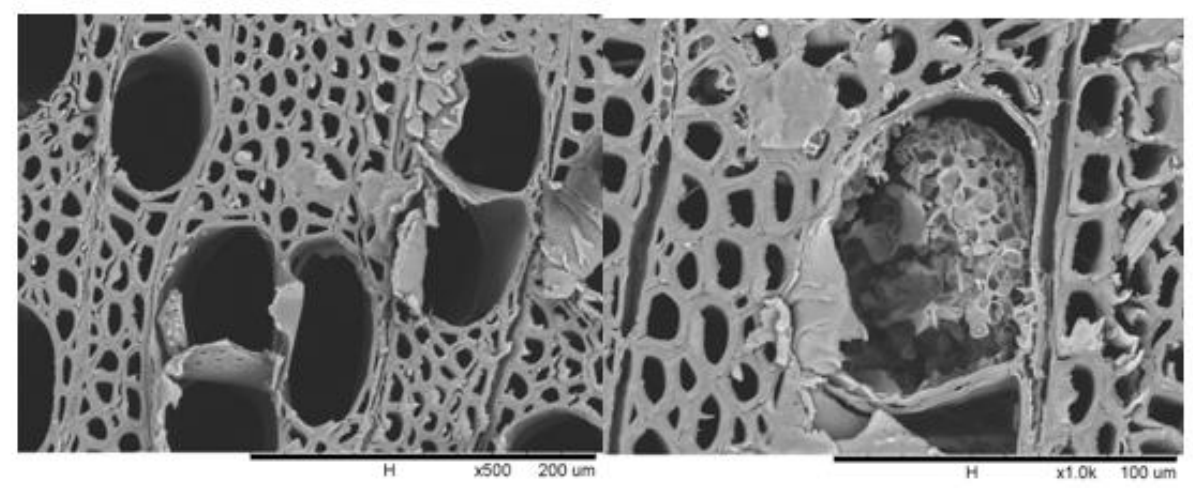

a

b

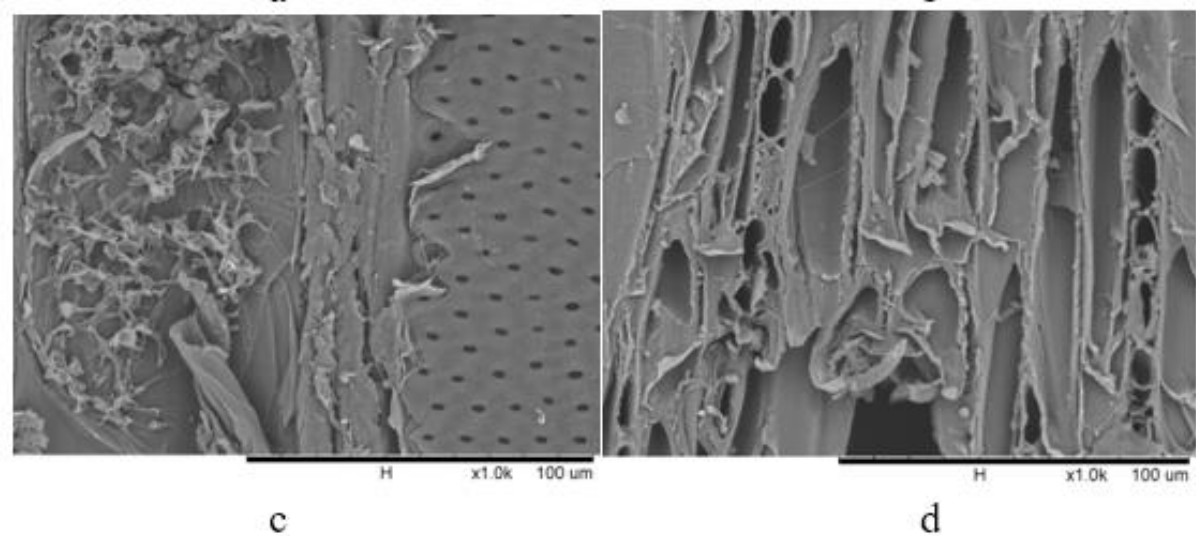

Figure 6. Influence of Xylaria venosula on wood structure of Aquilaria sinensis 
Figure 7 shows the growth of Xylaria venosula in the wood of Pinus kesiya, where a and $\mathrm{b}$ represent the mycelial distribution in the lumen of the duct and wood fibre, and $\mathrm{c}$ represents the mycelial distribution on the pit in the radial section, $d$ represents the mycelial distribution of the vessel element and wood ray on the tangential section of Pinus kesiya.

Based on the results in Figures 3-7, no obvious rot was found in the samples, and the strain Xylaria venosula was grown along natural cavities such as wood ducts, wood fibres, and parenchyma cells, even crossing between adjacent cells with the pits as the passages. A large amount of mycelial distribution was seen in the lumen of the duct, but no signs of disrupting the cell wall. Xylaria venosula is a white rot fungus. It is an initial rot from the mycelial distribution and morphology, and has little effect on the strength of wood.

The mycelia were mainly concentrated in the duct, parenchyma cells and the fibre cells connected to the parenchyma cells. Some of the fibre cells were close to the mycelia but have few mycelia, mainly due to a small number of nutrients inside. These characteristics indicate that these fungal infestations on specimens are performed by means of minimal resistance and the fastest access to nutrients anatomically (Dai, 2012).
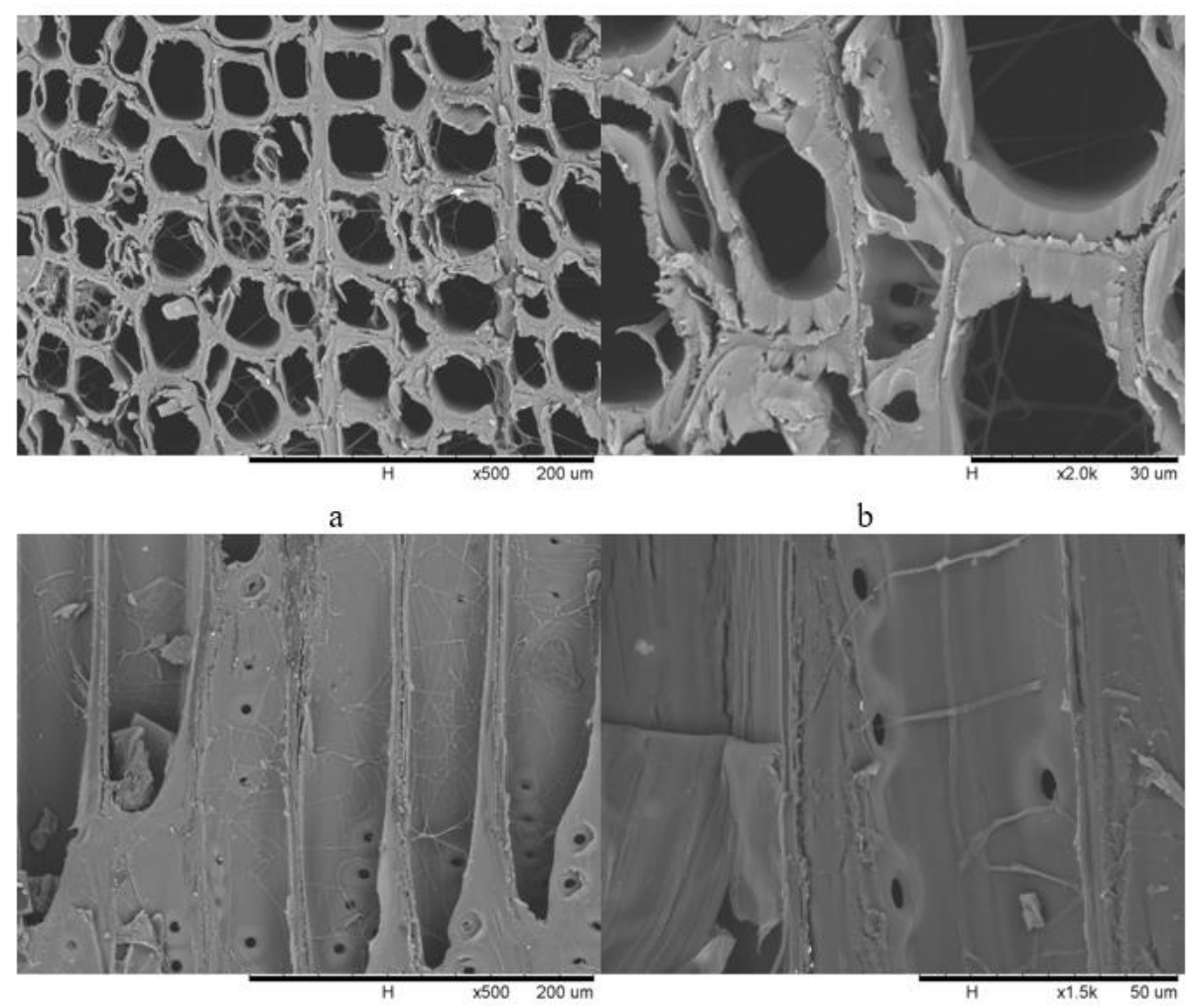

c

d

Figure 7. Influence of Xylaria venosula on the wood structure of Pinus kesiya

There is a certain amount of mycelium inside the zone lines, but significantly less than the centre of the zone lines; outside the zone lines the mycelium may exist or not. The zone lines appear in the same colour as the mycelium itself entangled in a group and they're formed by the secreted pigment layer in the cell cavity and cell wall. One 
common feature is the mycelia in the rotten area were denser than outside, and the peak density appeared at the centre of decayed area. This just proves that the formation of the zone lines is closely related to the water content of wood rot fungi, especially white rot fungus. There were some closed areas at the zone lines, which could provide the most suitable humidity for the fungi in the wood incubated area, because pseudo-bacterial nucleus produced by the fungus restricts the evaporation of water on the surface of the closed region, or maybe the boundary formed by the contact of two different mycelium also plays the same role (Nagy et al., 2012; Dai et al., 2012). The melanin secreted by the fungus has certain toxicity and is resistant to attack of other microorganisms. Thus, the rotten area in the wood is a barrier that the fungus uses to resist the invasion of other microorganisms so that it can keep utilizing the resources in the enclosed area. Almost all mycelia enter the adjacent cells through the pits of the wood's natural channel, which does not cause a significant decrease in the strength of the wood so that the 8-month-old spalted wood can fully meet the requirements for the production of handicrafts.

\section{Effect of wood water content on the formation of spalts}

\section{Statistical analysis of the percentage of the spalts in the area of wood block}

Figure 8 shows the percentage of external spalts on the four types of wood blocks infected by the strain Xylaria venosula under different water contents. Wood water content was evaluated using Equation 1. The SPSS one-way analysis of variance (ANOVA) $(\alpha=0.05, \mathrm{n}=30)$ showed that their external spalts were significantly different; when the water content reached $10 \%$, the area of spalts on the Aquilaria sinensis block by the strain Xylaria venosula was $3.72 \%$, which was the most serious spalting; when the water content reached $50 \%$, the spalt on the four wood blocks reached the largest, and that of Alnus nepalensis, Betula alnoides, Aquilaria sinensis and Pinus kesiya reached $6.35 \%, 5.81 \%, 6.64 \%$, and $6.23 \%$ respectively; but with the increase in water content, the external spalt on the blocks decreased, which is consistent with Yan Huang's research results (Huang et al., 2017); when the water content reached 90\%, the spalt area of Alnus nepalensis, Betula alnoides, Aquilaria sinensis and Pinus kesiya was reduced to $5.03 \%, 4.42 \%, 5.18 \%$ and $4.57 \%$. Studies have shown that when the water content of the wood block reaches $50 \%$, the living environment is most suitable for the growth of the strain Xylaria venosula, and the surface spalting is the most serious. Through comparing the four types of wood blocks, it is found that the external spalt on the Aquilaria sinensis wood block was the largest, and its spalting was the most serious, followed bythe Alnus nepalensis wood block, only $0.29 \%$ lower than that of Aquilaria sinensis.

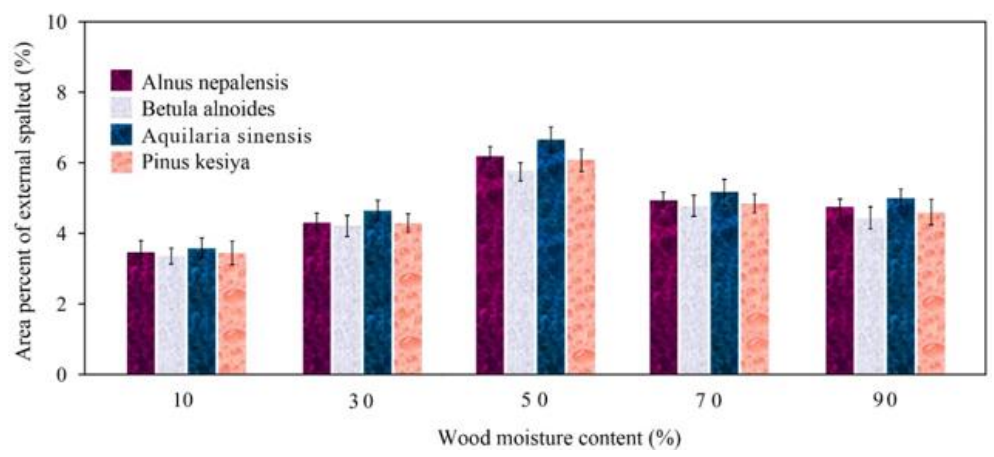

Figure 8. Percentage of surface spalts area formed by strains under different water contents 
Figure 9 shows the area percentage of the internal spalts in the four wood blocks formed by the strain Xylaria venosula under different water contents. The SPSS ANOVA $(\alpha=0.05, n=30)$ indicates that the area percentage of the internal zone lines was significantly different; when the water content reached $10 \%$, the percentage of the internal zone lines formed by the strain Xylaria venosula in the Aquilaria sinensis block was $0.4 \%$; when the water content reached $50 \%$, the area percentage of the internal spalts of the four blocks was the largest, the spalts percentage of Alnus nepalensis, Betula alnoides, Aquilaria sinensis and Pinus kesiya was 1.75\%, 1.61\%, 1.84\%, and $1.67 \%$, respectively; as the water content increases, the internal spalt area of blocks was reduced; when the water content reached 90\%, the spalt area of Alnus nepalensis, Betula alnoides, Aquilaria sinensis and Pinus kesiya decreased to 1.23\%, 1.09\%, 1.28\% and $1.17 \%$. Studies have shown that when the water content of the wood block is $50 \%$, this living environment is most suitable for the growth of the strain Xylaria venosula, and the internal zone line is the largest; among the four types of blocks, the internal spalts of Aquilaria sinensis are most obvious; that of the Alnus nepalensis block was second, 0.19 lower than Aquilaria sinensis.

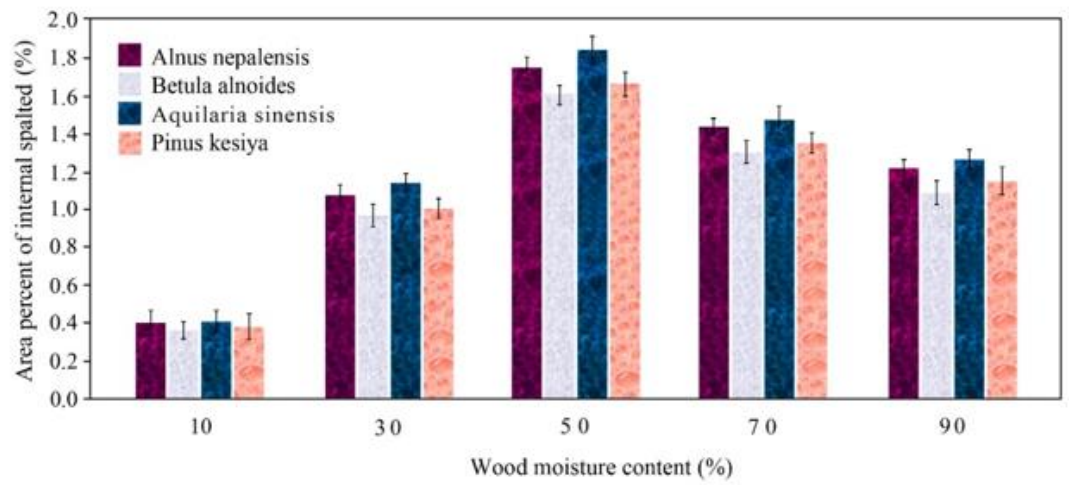

Figure 9. Percentage of internal spalts formed by strains at different water contents

The average mass loss percentage was evaluated using Equation 1. The fibre saturation point of the wood block is generally $30 \%$. When the water content of the wood block exceeded 30\%, free water molecules were present in the cell cavity for fungal growth and utilization; when it was below 30\%, there were very few free water molecules in the cell cavity, which is not conducive to fungal growth; when it was too high, the free water of the cell cavity occupied the lumen of the wood cell, with an extremely low air content, which is also unfavourable for the growth of the fungus.

When the water content of the wood block was 30-50\%, there was certain free water in the cell cavity, but still more air inside. The cell cavity was like a capillary tube, in which the free water keeps moving. In order to maintain the moisture required for its own growth, the fungus forms zone lines or stains to prevent the moisture movement, which is the main reason for the formation of large spalts.

\section{Mass loss rate of wood block}

Figure 10 shows the mass loss rates of the spalted woods obtained by the strain Xylaria venosula under different water contents of four wood specimens. It is found that the maximum value was $6.39 \%$, the minimum value was $4.36 \%$, and the average mass 
loss was $5.15 \%$, with little mass loss. The following results were obtained using the SPSS one-way analysis of variance $(\alpha=0.05, \mathrm{n}=5)$.

The strain Xylaria venosula has the highest mass loss rate under the water content $50 \%$ of wood blocks, and the lowest mass loss rate under the water content of $10 \%$. The strain Xylaria venosula had certain differences in mass loss rate under the different water contents of the four wood specimens. The mass loss rate of the Betula alnoides block was the highest, reaching $6.69 \%$, which exceeded that of Aquilaria sinensis block by $0.62 \%$, while the mass loss rate of Aquilaria sinensis was second to it.

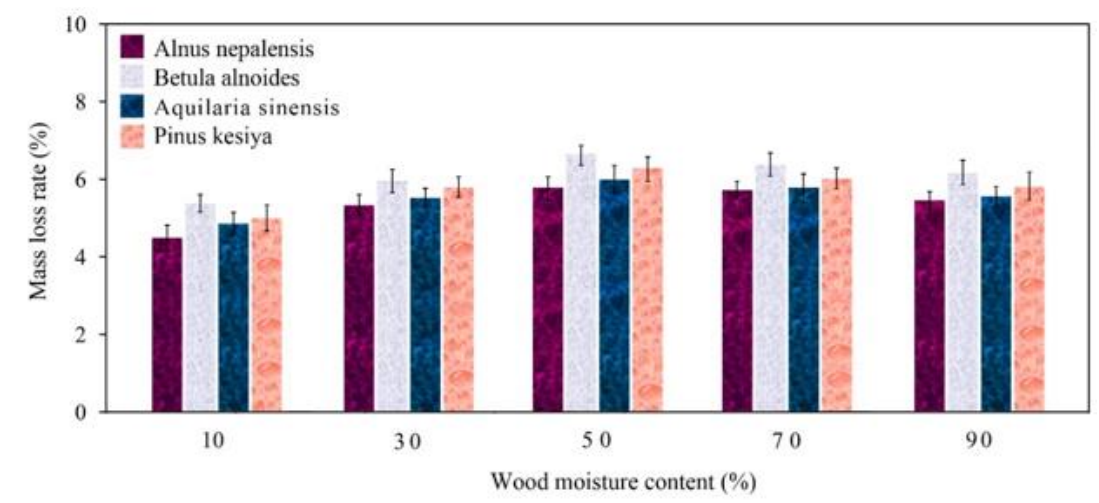

Figure 10. Average mass loss rate of spalted wood under the condition of different water contents

\section{Effect of strain Xylaria venosula on the mass loss rate and the parallel-to-grain compressive strength}

Result of the experimental was evaluated using Equation 3. Table 1 shows the results of weight loss rate and compressive strength parallel to grain of the spalted woods varying with the rotted time through the experiment, in which these four types of wood blocks were infested with Xylaria venosula strain for 4, 6, 8, 10, and 12 weeks at a water content of 50\%, and 12 pieces were weighed every 2 weeks, for a total of 240 pieces. It can be seen that with the increase of rotten time, the weight loss rate of the spalted wood was on the rise, and its compressive strength parallel to grain was correspondingly reduced, which is consistent with the research results of Daniela Tudor (Hladki and Romero, 2010).

Unitary linear recursive analysis was conducted about the weight loss rate and compressive strength of the four tree species using SPSS18.0 software. Table 2 lists the correlation coefficients of Alnus nepalensis, in which the Pearson correlation coefficient between the two variables was -0.986 , indicating a highly linear correlation between the two. Table 3 lists the linear equation coefficients. It can be seen that the regression coefficients in the regression model are: the constant of 67.739, and the independent variable mass loss rate of -3.613 . Then, the regression equation is given as:

$$
y=-3.613 x+67.73
$$

Table 1 also indicates that the weight loss rate of the four tree species has a linear relationship with the compressive strength. Their regression equation is shown in Figure 11. 
Table 1. Effect of the spalted wood on the weight loss rate and the compressive strength parallel to grain

\begin{tabular}{c|c|c|c|c|c|c|c}
\hline \multirow{2}{*}{ Tree species } & \multirow{2}{*}{ Character } & \multicolumn{7}{c}{ Decay time/week } \\
\cline { 3 - 8 } & & $\mathbf{0}$ & $\mathbf{4}$ & $\mathbf{6}$ & $\mathbf{8}$ & $\mathbf{1 0}$ & $\mathbf{1 2}$ \\
\hline \multirow{2}{*}{ Alnus nepalensis } & Weightlessness rate /\% & 0 & 2.49 & 2.89 & 3.35 & 3.76 & 3.83 \\
& Compressive strength /MPa & 68.18 & 57.25 & 56.87 & 56.72 & 54.15 & 54.02 \\
\hline \multirow{2}{*}{ Betula alnoides } & Weightlessness rate /\% & 0 & 1.59 & 2.11 & 2.55 & 2.97 & 3.34 \\
& Compressive strength /MPa & 117.69 & 99.62 & 95.10 & 92.12 & 91.19 & 90.91 \\
\hline \multirow{2}{*}{ Aquilaria sinensis } & Weightlessness rate /\% & 0 & 2.18 & 2.97 & 3.31 & 3.75 & 4.01 \\
& Compressive strength /MPa & 96.28 & 93.67 & 93.36 & 89.49 & 81.31 & 77.84 \\
\hline \multirow{2}{*}{ Pinus kesiya } & Weightlessness rate /\% & 0 & 1.32 & 1.70 & 1.98 & 2.11 & 2.35 \\
& Compressive strength /MPa & 117.48 & 113.04 & 112.54 & 108.21 & 108.01 & 105.91 \\
\hline
\end{tabular}

Table 2. Correlation coefficients

\begin{tabular}{|c|c|c|c|}
\hline \multicolumn{2}{|r|}{ Character } & $\begin{array}{c}\text { Compressive strength } \\
\text { of Alnus nepalensis }\end{array}$ & $\begin{array}{l}\text { Weightlessness rate of } \\
\text { Alnus nepalensis }\end{array}$ \\
\hline \multirow{2}{*}{$\begin{array}{l}\text { Pearson } \\
\text { correlation }\end{array}$} & Compressive strength of Alnus nepalensis & 1.000 & -.986 \\
\hline & Weightlessness rate of Alnus nepalensis & -.986 & 1.000 \\
\hline \multirow{2}{*}{$\begin{array}{c}\text { Sig. } \\
\text { (single side) }\end{array}$} & Compressive strength of Alnus nepalensis & • & .000 \\
\hline & Weightlessness rate of Alnus nepalensis & .000 & . \\
\hline \multirow{2}{*}{$\mathrm{N}$} & Compressive strength of Alnus nepalensis & 6 & 6 \\
\hline & Weightlessness rate of Alnus nepalensis & 6 & 6 \\
\hline
\end{tabular}

Table 3. Model coefficients

\begin{tabular}{c|c|c|c|c|c|c|c|c}
\hline \multicolumn{2}{c}{ Model } & $\begin{array}{c}\text { Non-standardized } \\
\text { coefficient }\end{array}$ & \multirow{2}{*}{$\begin{array}{c}\text { Standard } \\
\text { coefficient }\end{array}$} & \multirow{2}{*}{$\mathbf{t}$} & \multirow{2}{*}{ Sig. } & \multicolumn{2}{|c|}{$\begin{array}{c}\text { The 95.0\% confidence } \\
\text { interval of B }\end{array}$} \\
\cline { 2 - 9 } & B & $\begin{array}{c}\text { Standard } \\
\text { error (SE) }\end{array}$ & & & $\begin{array}{c}\text { Lower } \\
\text { bound }\end{array}$ & $\begin{array}{c}\text { Upper } \\
\text { bound }\end{array}$ \\
\hline \multirow{2}{*}{1} & (Constant) & 67.739 & .909 & & 74.549 & .000 & 65.216 & 70.262 \\
\cline { 2 - 9 } & $\begin{array}{c}\text { Weightlessness rate of } \\
\text { Alnus nepalensis }\end{array}$ & -3.613 & .300 & -.986 & -12.036 & .000 & -4.447 & -2.780 \\
\hline
\end{tabular}

The significant level of regression was 0.000 , indicating that the probability for regression coefficient equal to 0 in T-statistic test was 0.000 , and also that the linear correlation between the two variables is extremely significant, and the established regression equation is valid.

Figure 12 shows the measured cumulative probability p-p chart in the regression analysis, in which the scatter points are roughly scattered around the oblique line, so it can be approximated that the residual distribution is subject to a normal distribution.

Result of the experimental was evaluated using Equation 4. Table 4 shows the correlation coefficients of the Betula alnoides, in which the Pearson correlation coefficient between the two variables was -0.968 , indicating a highly linear correlation between the two. Table 5 lists the linear equation coefficients. It can be seen that the 
regression coefficients in the regression model are: 115.232 for constant, and -8.297 for the independent variable mass loss rate. Then, the regression equation is given as:

$$
y=-8.297 x+115.232
$$

The significant level of regression was 0.002 for the weight loss rate of the Betula alnoides, and it was 0.000 for the compressive strength, indicating that the probability of regression coefficient equal to 0 in the t-statistical test that was 0.002 and 0.000 , respectively, and also the linear correlation between the two variables is extremely significant and the established regression equation is valid.
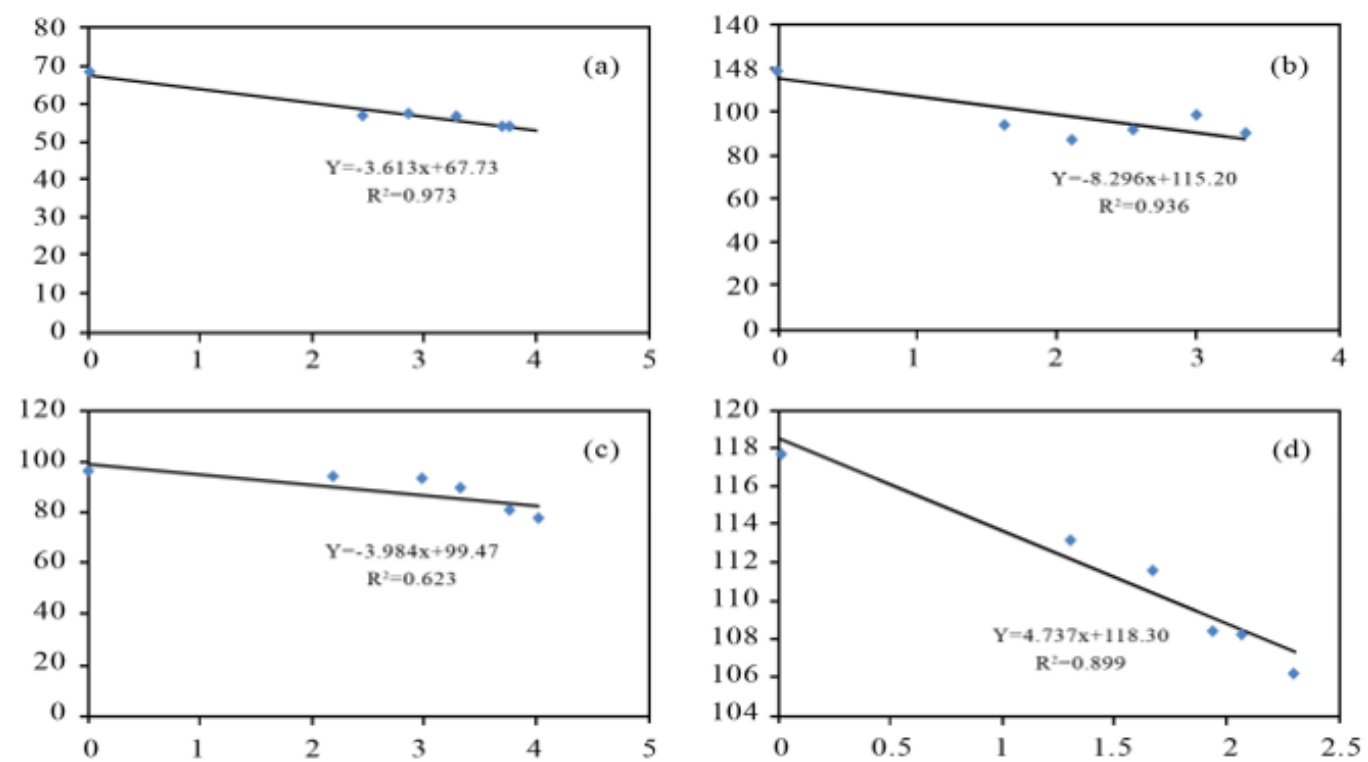

Figure 11. Regression analysis for weight loss rate and compressive strength of tree species

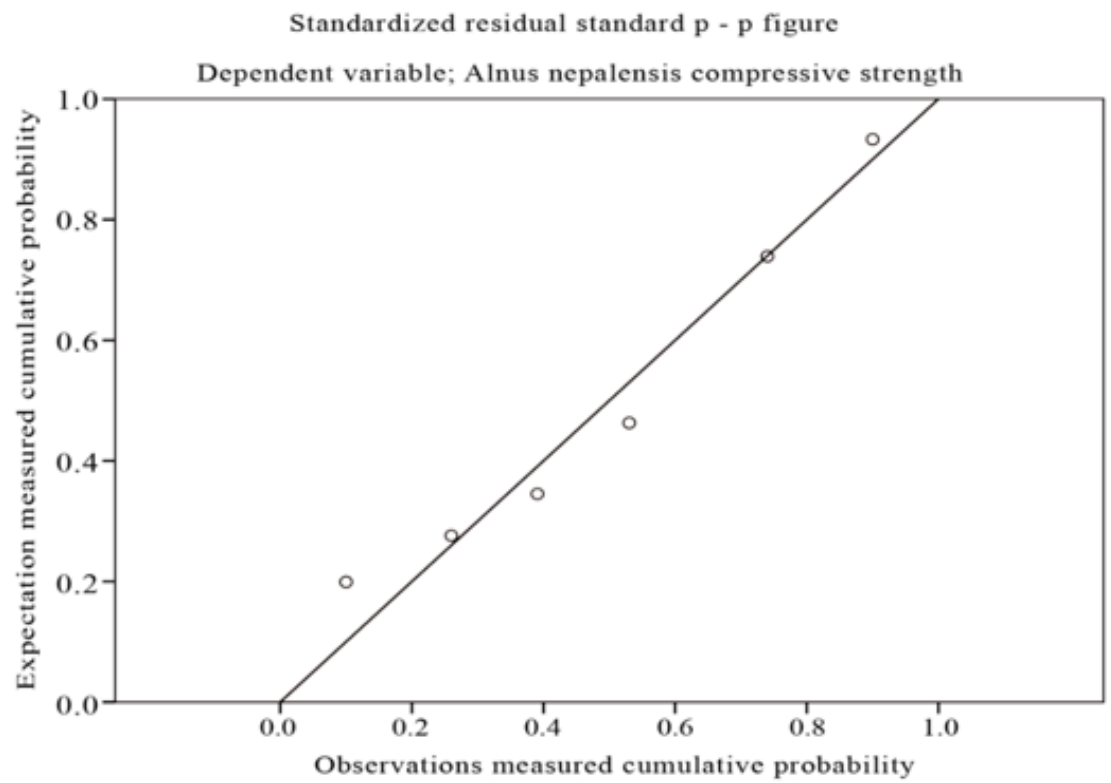

Figure 12. Measured cumulative probability 
Table 4. Correlation coefficients

\begin{tabular}{c|c|c|c}
\hline \multicolumn{2}{c|}{ Character } & $\begin{array}{c}\text { Compressive strength } \\
\text { of Betula alnoides }\end{array}$ & $\begin{array}{c}\text { Weightlessness rate } \\
\text { of Betula alnoides }\end{array}$ \\
\hline $\begin{array}{c}\text { Pearson } \\
\text { correlation }\end{array}$ & $\begin{array}{c}\text { Compressive strength of Betula alnoides } \\
\text { Weightlessness rate of Betula alnoides }\end{array}$ & 1.000 & -.968 \\
\hline $\begin{array}{c}\text { Sig. } \\
\text { (single side) }\end{array}$ & Compressive strength of Betula alnoides & -.968 & 1.000 \\
\hline \multirow{2}{*}{$\mathrm{N}$} & Weightlessness rate of Betula alnoides &. & .001 \\
& Compressive strength of Betula alnoides & .001 &. \\
\hline
\end{tabular}

Figure 13 shows the measured cumulative probability p-p chart in the regression analysis, in which the scatter points are roughly scattered around the oblique line, so it can be approximated that the residual distribution is subject to a normal distribution.

Result of the experimental was evaluated using Equation 5. Tables 6 and 7 show the correlation coefficients of the Aquilaria sinensis, in which the Pearson correlation coefficient between the two variables was -0.790 , indicating a highly linear correlation between the two. Table 5 lists the linear equation coefficients. It can be seen that the regression coefficients in the regression model are: 99.472 for constant, and -3.985 for the independent variable mass loss rate. Then, the regression equation is given as:

$$
y=-3.985 x+99.472
$$

The significant level of regression was 0.062 for the weight loss rate of the Aquilaria sinensis, and it was 0.000 for the compressive strength, indicating that the probability of regression coefficient equal to 0 in the t-statistical test that is 0.062 and 0.000 , respectively, and also the linear correlation between the two variables is extremely significant and the established regression equation is valid.

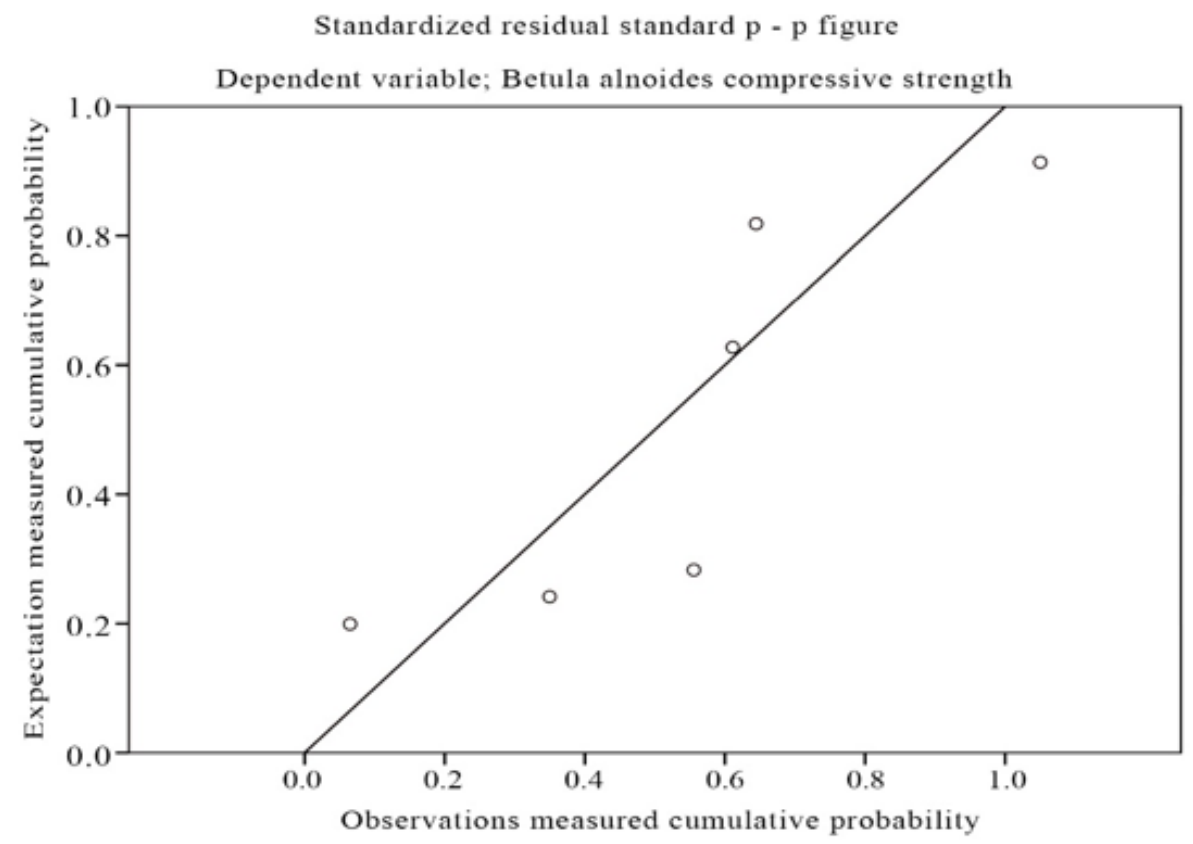

Figure 13. Measured cumulative probability 
Table 5. Model coefficient

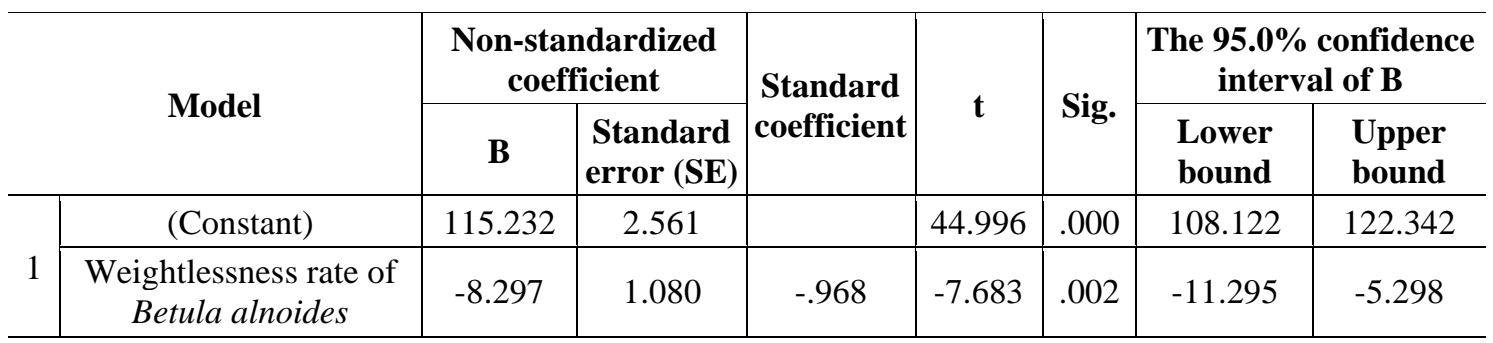

Dependent variable: compressive strength of Betula alnoides

Table 6. Correlation and checklist

\begin{tabular}{c|c|c|c}
\hline \multicolumn{2}{c|}{ Character } & $\begin{array}{c}\text { Compressive strength } \\
\text { of Aquilaria sinensis }\end{array}$ & $\begin{array}{c}\text { Weightlessness rate } \\
\text { of } \text { Aquilaria sinensis }\end{array}$ \\
\hline $\begin{array}{c}\text { Pearson } \\
\text { correlation }\end{array}$ & Compressive strength of Aquilaria sinensis & 1.000 & -.790 \\
\hline $\begin{array}{c}\text { Sig. } \\
\text { (single side) }\end{array}$ & Weightlessness rate of Aquilaria sinensis & -.790 & 1.000 \\
\hline \multirow{2}{*}{$\mathrm{N}$} & Weightlessness rate of Aquilaria sinensis &. & .031 \\
& Compressive strength of Aquilaria sinensis & .031 &. \\
\hline
\end{tabular}

Table 7. Model coefficient

\begin{tabular}{|c|c|c|c|c|c|c|c|c|}
\hline & \multirow{2}{*}{ Model } & \multicolumn{2}{|c|}{$\begin{array}{c}\text { Non-standardized } \\
\text { coefficient }\end{array}$} & \multirow{2}{*}{$\begin{array}{c}\text { Standard } \\
\text { coefficient }\end{array}$} & \multirow{2}{*}{$\mathbf{t}$} & \multirow{2}{*}{ Sig. } & \multicolumn{2}{|c|}{$\begin{array}{c}\text { The } 95.0 \% \text { confidence } \\
\text { interval of B }\end{array}$} \\
\hline & & & Stan & & & & Lower & Upper \\
\hline \multirow[b]{2}{*}{1} & (Constant) & 99.472 & 4.685 & & 21.234 & .000 & 86.465 & 112.478 \\
\hline & $\begin{array}{l}\text { Weightlessness rate of } \\
\text { Aquilaria sinensis }\end{array}$ & -3.985 & 1.547 & -.790 & -2.575 & .062 & -8.281 & .311 \\
\hline
\end{tabular}

Dependent variable: compressive strength of Aquilaria sinensis

Figure 14 shows the measured cumulative probability p-p chart in the regression analysis, in which the scatter points are roughly scattered around the oblique line, so it can be approximated that the residual distribution is subject to a normal distribution.

Result of the experimental was evaluated using Equation 6. Tables 8 and 9 shows the correlation and coefficients of the Pinus kesiya, in which the Pearson correlation coefficient between the two variables is -0.948 , indicating a highly linear correlation between the two. Table 9 lists the linear equation coefficients. It can be seen that the regression coefficients in the regression model are: 118.381 for constant, and -4.738 for the independent variable mass loss rate. Then, the regression equation is given as:

$$
y=-4.738 x+118.381
$$

The significant level of regression was 0.004 for the weight loss rate of the Pinus kesiya, and it was 0.000 for the compressive strength, indicating that the probability of 
regression coefficient equal to 0 in the t-statistical test that is 0.004 and 0.000 , respectively, and also the linear correlation between the two variables is extremely significant and the established regression equation is valid.

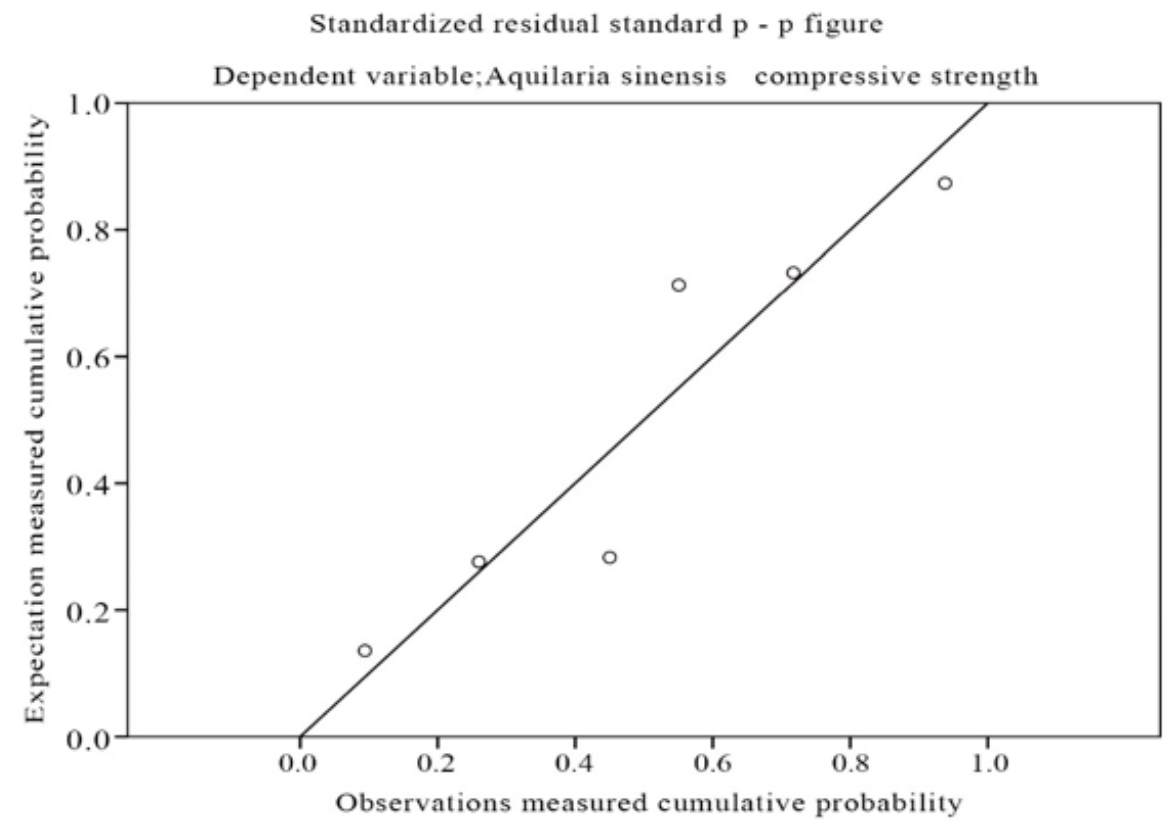

Figure 14. Measured cumulative probability

Figure 15 shows the measured cumulative probability p-p chart in the regression analysis, in which the scatter points are roughly scattered around the oblique line, so it can be approximated that the residual distribution is subject to a normal distribution.

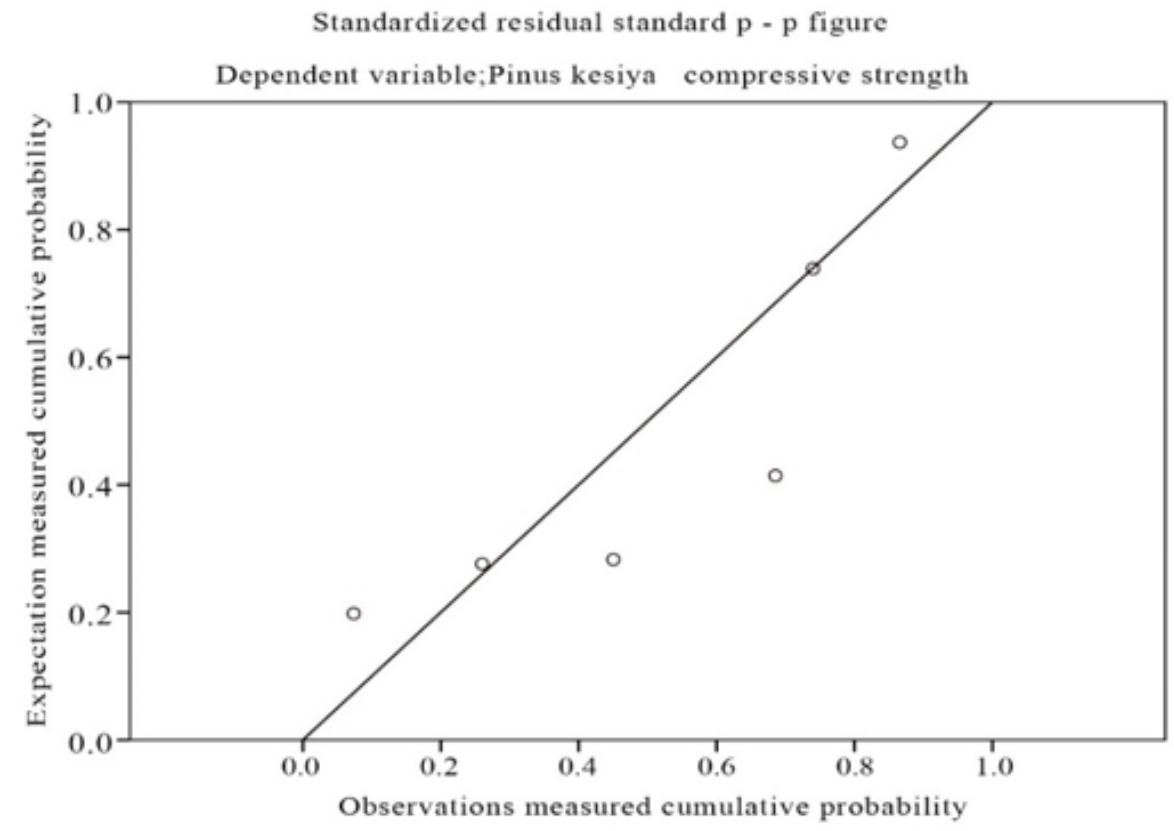

Figure 15. Measured cumulative probability 
Table 8. Correlation coefficients

\begin{tabular}{c|c|c|c}
\hline \multicolumn{2}{c|}{ Character } & $\begin{array}{c}\text { Compressive strength } \\
\text { of Pinus kesiya }\end{array}$ & $\begin{array}{c}\text { Weightlessness rate of } \\
\text { Pinus kesiya }\end{array}$ \\
\hline $\begin{array}{c}\text { Pearson } \\
\text { correlation }\end{array}$ & Compressive strength of Pinus kesiya & 1.000 & -.948 \\
\hline $\begin{array}{c}\text { Sig. } \\
\text { (single side) }\end{array}$ & Weightlessness rate of Pinus kesiya & -.948 & 1.000 \\
\hline \multirow{2}{*}{ N } & Weightlessness rate of Pinus kesiya &. & .002 \\
& Compressive strength of Pinus kesiya & .002 &. \\
\hline
\end{tabular}

Table 9. Model coefficients

\begin{tabular}{|c|c|c|c|c|c|c|c|c|}
\hline & \multirow{2}{*}{ Model } & \multicolumn{2}{|c|}{$\begin{array}{c}\text { Non-standardized } \\
\text { coefficient }\end{array}$} & \multirow{2}{*}{$\begin{array}{l}\text { Standard } \\
\text { coefficient }\end{array}$} & \multirow{2}{*}{$\mathbf{t}$} & \multirow{2}{*}{ Sig. } & \multicolumn{2}{|c|}{$\begin{array}{l}\text { The } 95.0 \% \text { confidence } \\
\text { interval of } B\end{array}$} \\
\hline & & & Standard & & & & Lower & Upper \\
\hline \multirow[b]{2}{*}{1} & (Constant) & 118.381 & 1.402 & & 84.442 & .000 & 114.489 & 122.274 \\
\hline & $\begin{array}{c}\text { Weightlessness rate of } \\
\text { Pinus kesiya }\end{array}$ & -4.738 & .794 & -.948 & -5.969 & .004 & -6.942 & -2.534 \\
\hline
\end{tabular}

Dependent variable: compressive strength of Pinus kesiya

In summary, the unitary linear regression analysis shows that the correlation between the weight loss rate and the compressive strength parallel to grain is very significant, and both are highly negatively correlated. The weight loss rate of the specimens did not change much; with the increase of rotten time, the weight loss rate of the specimens was on the rise; while the compressive strength parallel to grain of the spalted woods was gradually reduced. The strain Xylaria venosula does not destroy the internal cell wall of the spalted wood, and has little effect on the strength of the wood, since it is an initial decay in terms of the mycelial distribution and morphology.

\section{Conclusions}

Spalting is the coloration of wood caused by fungal colonization with beautiful patterns, it can be made into green, low-carbon, environmentally friendly and nice decorative crafts and wood veneer products, so as to enhance the rate of multipurpose utilization and additional value, it is provided with a very high economic value.

This paper aims to carry out a preliminary study and discussion on the spalted woods with zone lines induced artificially by fungi and the related mechanism. For this purpose, the strain Xylaria venosula was selected and inoculated into the wood blocks for preparing the spalted wood. Then, using the light and electron microscopy, it analyses the microfeatures of the spalted wood, and conducts experiments on the measurement of compressive strength and the influence of wood water content on the spalt formation. Finally, the following conclusions were drawn:

(1) The microfeatures of the spalted woods were analysed by light and electron microscopy, revealing that Aquilaria sinensis could easily form black zone lines, which are mainly distributed in ducts, parenchyma cells and fibroblasts connected with 
parenchyma cells, indicating that these fungal infestations on specimens are performed by means of minimal resistance and the fastest access to nutrients anatomically; the mycelia inside the zone lines were denser than outside, and the peak density appeared at the centre of each zone line; the black zone lines in the wood is a barrier that the fungus uses to resist the invasion of other microorganisms, so that the resources in the enclosed area can be utilized continuously.

(2) Analysis for the effect of wood water content on the spalts formed by Xylaria venosula showed that when the water content of the wood was $50 \%$, the amount of external and internal spalts formed was the most and the most obvious, and the surface spalts formed on the four wooden blocks reached the maximum; The largest spalt was observed on Aquilaria sinensis blocks; this type of wood underwent the most serious spalting, with $6.64 \%$ of its surface and $1.84 \%$ of its interior covered by spalts. In this case, zone lines were rich and beautiful and the wood was not severely rotten. Thus, this wood and the water content offer the most suitable conditions for the growth of Xylaria venosula strains.

(3) The measured results of mean mass loss percentage and compressive strength show that as the wood blocks rotted over time, the weight loss rates of spalted woods were on the rise, while the compressive strengths parallel to grain were gradually falling. When the water content was $10 \%$, the mass loss rate of the specimen was the smallest; when it was 50\%, the mass loss rate of Aquilaria sinensis was large, reaching $6.07 \%$, but lower than Alnus nepalensis.

(4) The compressive strength measurement showed that the weight loss rate of Alnus nepalensis was increased with rotten time, and the compressive strength of the spalted wood was correspondingly reduced. A linear regression analysis was conducted about the weight loss rate and the compressive strength parallel to grain of the artificially prepared spalted wood, to find that the correlation between the two was very significant and also highly negatively correlated. Also, there was no sign of destroying the cell wall inside the spalted wood formed by the strain Xylaria venosula. In terms of distribution and morphology, the mycelium was an initial decay and had little effect on the strength of the wood.

To sum up, the spalted wood cultivated by artificially inoculated Xylaria venosula has good stability, natural and beautiful pattern, and low corrosiveness. It has no big effect on mass loss rate and the compressive strength of wood blocks. Therefore, it has a good prospect for the use of the strain Xylaria venosula to prepare the spalted wood has a good prospect which is suitable for application and promotion.

These contents will become the next study. First, directional generation of zone lines. Then, the generation time of zone lines will shorted.

Acknowledgements. This work was financially supported by the National Natural Science Foundation of China (Grant No. 31570555)

\section{REFERENCES}

[1] Dai, Y. C. (2012): Polypore diversity in China with an annotated checklist of Chinese polypores. - Mycoscience 53(1): 49-80.

[2] Fournier, J., Flessa, F., Peršoh, D., Stadler, M. (2011): Three new Xylaria species from southwestern Europe. - Mycological Progress 10(1): 33-52. 
[3] Hladki, A. I., Romero, A. I. (2010): A preliminary account of Xylaria in the Tucuman Province, Argentina, with a key to the known species from the Northern Provinces. Fungal Diversity 42(1): 79-96.

[4] Huang, Y., Finell, M., Larsson, S., Wang, X., Zhang, J., Wei, R., Liu, L. (2017): Biofuel pellets made at low moisture content-Influence of water in the binding mechanism of densified biomass. - Biomass and Bioenergy 98: 8-14.

[5] Læssøe, T., Srikitikulchai, P., Luangsa-ard, J. J. D., Stadler, M. (2013): Theissenia reconsidered, including molecular phylogeny of the type species T. Pyrenocrata and a new genus Durotheca (Xylariaceae, Ascomycota). - IMA Fungus 4(1): 57-69.

[6] Liers, C., Ullrich, R., Steffen, K. T., Hatakka, A., Hofrichter, M. (2006): Mineralization of $14 \mathrm{C}$-labelled synthetic lignin and extracellular enzyme activities of the woodcolonizing ascomycetes Xylaria hypoxylon and Xylaria polymorpha. - Applied Microbiology and Biotechnology 69(5): 573-579.

[7] Nagy, N. E., Ballance, S., Kvaalen, H., Fossdal, C. G., Solheim, H., Hietala, A. M. (2012): Xylem defense wood of Norway spruce compromised by the pathogenic whiterot fungus Heterobasidion parviporum shows a prolonged period of selective decay. Planta 236(4): 1125-1133.

[8] Osono, T., To-Anun, C., Hagiwara, Y., Hirose, D. (2011): Decomposition of wood, petiole and leaf litter by Xylaria species from northern Thailand. - Fungal Ecology 4(3): 210-218.

[9] Passarini, M. R., Santos, C., Lima, N., Berlinck, R. G., Sette, L. D. (2013): Filamentous fungi from the Atlantic marine sponge Dragmacidon reticulatum. - Archives of Microbiology 195(2): 99-111.

[10] Pearce, R. B. (1984): Staining fungal hyphae in wood. - Transactions of the British Mycological Society. https://doi.org/10.1016/S0007-1536(84)80029-7.

[11] Robinson, S. C., Laks, P. E. (2010): Culture age and wood species affect zone line production of Xylaria polymorpha. - Mycological Research in Review 4: 18-21.

[12] Robinson, S. C., Richter, D. L., Laks, P. E. (2007): Colonization of sugar maple by spalting fungi. - Forest Products Journal 57(4): 24

[13] Robinson, S. C., Laks, P. E., Turnquist, E. J. (2009): A method for digital color analysis of spalted wood using Scion Image software. - Materials 2(1): 62-75.

[14] Robinson, S. C., Tudor, D., Cooper, P. A. (2011): Feasibility of using red pigment producing fungi to stain wood for decorative applications. - Canadian Journal of Forest Research 41(8): 1722-1728.

[15] Tian, J. J., Gao, X. X., Zhang, W. M., Wang, L., Qu, L. H. (2013): Molecular identification of endophytic fungi from Aquilaria sinensis and artificial agarwood induced by pinholes-infusion technique. - African Journal of Biotechnology 12(21).

[16] Tudor, D., Robinson, S. C., Cooper, P. A. (2012): The influence of moisture content variation on fungal pigment formation in spalted wood. - AMB Express 2(1): 69.

[17] Tudor, D., Robinson, S. C., Cooper, P. A. (2013): The influence of pH on pigment formation by lignicolous fungi. - International Biodeterioration \& Biodegradation 80: 2228.

[18] Xu, Y., Zhang, Z., Wang, M., Wei, J., Chen, H., Gao, Z., Meng, H. (2013): Identification of genes related to agarwood formation: Transcriptome analysis of healthy and wounded tissues of Aquilaria sinensis. - BMC Genomics 14(1): 227.

[19] Zink, P., Fengel, D. (1988): Studies on the colouring matter of blue-stain fungi. Part 1. General characterization and the associated compounds. - Holzforschung - International Journal of the Biology, Chemistry, Physics and Technology of Wood 42(4): 217-220. 